\title{
Qualified Safety Management Ensures Sustainable Human Life Quality
}

\author{
Dana Procházková \\ Czech Technical University in Prague \\ Faculty of Transportation Sciences \\ Konviktská 20,110 00 Prague 1, Czech Republic \\ prochazkova@fd.cvut.cz
}

\begin{abstract}
The quality of both, the safety management and the ways of realisation of management tasks, are fundamental importance for ensuring the human security and sustainable development. The capability of correct application of risk management process is important. For assembling the qualified data for the FOCUS, the EU project, it was proposed the tool that leans on method of application of case study at decision-making. The tool has four main parts and it acts for obtaining the qualified groundwork for territory safety management and it can be easy adapted for needs of objects, partial safeties as it is the labour safety and health, and organisations. The paper shows aims of individual steps and linking the partial tools from management domain.
\end{abstract}

Keywords: safety management, FOCUS, sustainability, security.

\section{Introduction}

Present goal of humans is their security and sustainable development. In agreement with the EU and UN proclamations, the professional knowledge and experience, there is necessary for human society conservation and sustainable development to create the safe territory, safe community, safe state, safe Europe and safe world. The safe space undoubtedly includes the quality environment, on which the human lives are strongly dependent. For investigation purposes, the safe space is represented by safe open dynamically variable system that we denote in agreement with the UN report from 1994 [1] as the Human System. The environment is also the system and from the general view we can say that the environmental system is understood as biosphere elements which include the atmosphere, the hydrosphere, the lithosphere and the ecosphere, the set of interactions among these elements that are caused by links and flows among elements [2]. In detail, both systems are system of systems (SoS), i.e. several overlapping systems [3].

Safety of each system is disturbed by disasters, i.e. internal or external phenomena that lead or can lead to damages, harms and losses on system assets and on system oneself. The sources of some disasters are also inherently connected with human lives and activities [3]. It means that both systems under account (the environmental system and the human system) are affected by both, the processes, actions and phenomena 
that are under way in human society, environment, planet system, galaxy and other higher systems, and the human management acts.

The basic terms of each system safety management [3] are:

Security is a state of system at which the occurrence of harm or loss on system assets has an acceptable probability (it is almost sure that harm and loss do not origin). To this there is also belonged a certain stability of system in time and space, i.e. a sustainable development in time and space.

Safety is a set of human measures and activities for ensuring the security and sustainable development of system and its assets (protected interests).

Secure system is a system that is protected against to internal and external disasters.

Safe system is a system that is protected against to internal and external disasters and it does not threaten its vicinity.

Safe environment is an environment which is secure and it can sustainable develop.

Safe human system represented by safe territory including the human society, is a human system, the assets of which are public assets (Figure 1) being in security and with potential of sustainable development. Similarly safe organisation is the organisation, the assets of which are in security and they can sustainable develop; the organisation assets are public assets and specific assets directly connected with organisation existence [3].

Human system safety management is the management of human system directed to human system safety, the product of which is security and sustainable development of all public assets denoted in Figure 1 [3].

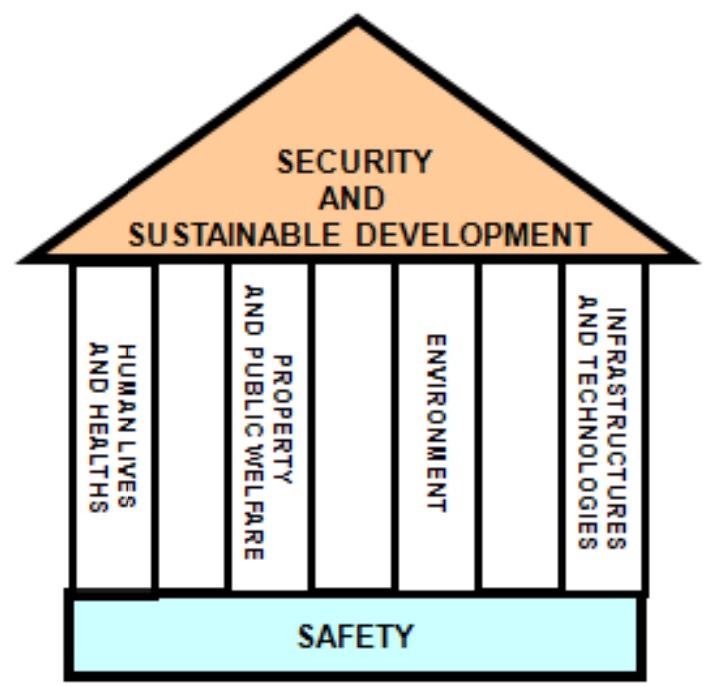

Fig. 1. Human system safety management process model and its public assets (Source: [3])

By analogy, the environmental system safety management denoted in main professional sources (www.epa.gov.ems/, www.inem.org) only as an environmental 
management is realised by an environmental management system (EMS). It refers to the management of an organization's environmental programs in a comprehensive, systematic, planned and documented manner. It includes the organisational structure, planning and resources for developing, implementing and maintaining policy for environmental protection. According to rules given in materials presented in www.epa.gov.ems/, www.inem.org) it:

- serves as a tool to improve environmental performance,

- provides a systematic way of managing an subject's environmental affairs,

- is the aspect of the subject's overall management structure that addresses immediate and long-term impacts of its products, services and processes on the environment,

- gives order and consistency for organizations to address environmental concerns through the allocation of resources, assignment of responsibility and on-going evaluation of practices, procedures and processes,

- focuses on continual improvement of the system.

It means that it deals with an organisation or territory safety management with the asset "environment".

Enthusiasm that was in developed countries in the middle of last century, when humans believed that the human kind would have power over disasters (wind, rain, earthquake etc.), was replaced step by step during the time by respect to the Earth's Planet System. At present the human actions and management are implemented by a pragmatic approach based on evaluation of credible and relevant data and the humans take into account that their knowledge and capabilities are:

- too small to prevent the origination of disasters that are the manifestation of the Earth's Planet System development,

- adequate to mitigate the impacts of disasters that are the manifestation of the Earth's Planet System development,

- sufficient to prevent the origination of disasters that are connected with the human actions and with development of human society (so called man-made).

Generally, there is known that every time when we want to control some phenomenon or to avert it, we must know its cause, size, repeat and nature of impact effects on assets. The disaster sizes, namely extreme ones have basic importance for a system safety. From them it is unreeled the created protection system, i.e. the system of measures and activities for averting or mitigating the disasters and / or their impacts [3].

There is necessary to take into account that disasters from the viewpoint of the Planet or environment development might be inventive changes supporting these system states and that human with his / her wishes and management goes against them. If it is reasonable and profitable for humans in near or distant future, we cannot estimate because our fittings in this domain are very poor and such question has been only recently appeared in a professional domain. Therefore, there is necessary to use the precaution principle in each system management. This principle is inherently included in safety management that denotes the strategic management ensuring the identification, diagnose, enforcement and implementation [4]. According to present 
knowledge the processes, induced the disasters in both considered systems, are given and characterize in [3]. At the disaster occurrence there are originated chains of undesirable phenomena (impacts, consequences) of external and internal character, primary and secondary, which affect negatively system assets with different intensities and in different time moments. The substantial role plays the local vulnerability and pertinent faults in a human behaviour or a management on all levels. The disasters are the cause of emergency situations, the severity of which substantially increases if cascade impacts occur, see data in [3]. Regarding to present knowledge and experience each system safety management has to arrange to:

- precede disasters if possible, e.g. in a case of natural disasters it is impossible,

- eliminate the causes of severe disaster impacts or at least to reduce their occurrence frequency,

- mitigate unacceptable disaster impacts by preventive measures, preparedness, optimal defeating the disaster impacts and by them defeating the induced critical situations (i.e. really the reducing the emergency duration to acceptable amount),

- ensure renovation and start of further development of system considered.

It holds for both, the human system safety management [3] and for environmental management (www.epa.gov.ems/, www.inem.org). From the present knowledge viewpoint there is necessary to ensure in order that each system management directed to safety might be proactive, strategic and might consider facts, findings, experiences and their correct evaluation. The reactive management is only admissible on operative level when emergency or critical situations have been occurred, i.e. in times when there is necessary to solve problems immediately and when no time for deep analysis and assessments that are challenging for data, methods and processing time [5]. Therefore, in practice we realise third level safety management, Figure 2.

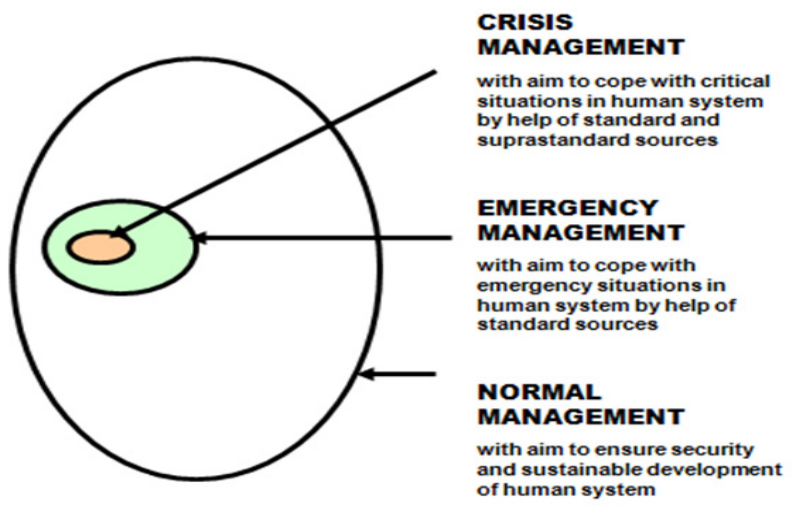

Fig. 2. Levels of safety management (Source: [3])

The paper deals with the relation between human system safety management and environmental management (in the sense of above given fact it goes on environmental system safety management but in the most professional sources the word "safety" is not given, and therefore, we respect it). 


\section{Risk and Safety Management Principles}

Strategy of management for ensuring the security and sustainable development of managed subject consists in negotiation with risks [6-7]. According to present possibilities of human society we apply several ways of negotiation with risk:

- part of risk is reduced, i.e. by preventive measures the risk realisation is averted,

- part of risk is mitigated, i.e. by preventive measures and by preparedness (warning systems and another measures of emergency and crisis management) there are reduced or averted non-acceptable impacts,

- part of risk is re-insured,

- part of risk for which response and renovation will be necessary there are prepared resources for response and renovation,

- part of risk for which there is only prepared contingency plan, i.e. this part of risk is non-controllable, too expensive or low frequent.

To this it is joined the distribution of risk defeating among all stakeholders [6]. The distribution in the good governance is performed according to a rule that all stakeholders have responsibility for risk defeat and that the defeat of real risk is assigned to a subject, the preparedness of which is the best.

For classical / standard risk management and for risk governance in a subject it is necessary:

1. To understand the process of disaster origination and the conditions, under which the process goes on.

2. To know the sites in which the disaster can originate and its probable physical and other characteristics.

3. To identify the hazard that disaster means for a given subject according to stipulated rules.

4. To determine the impacts of disaster with size equals to a hazard on assets.

5. To eliminate the unacceptable disaster impacts in cases in which it is possible with acceptable expenses.

6. For residual impacts to calculate by help of predictive models their occurrence probability, respecting the fact that there are also considered possible failures of preventive measures.

7. To calculate possible harms of assets in the considered subject with regard to assets, that are really in the subject considered and by help of occurrence probability to determine the risk size.

8. To identify and to realize the mitigation measures with regard to considered assets in the way that they may be ALARP (so low as reasonable achievable).

9. To prove that all measures for averting and mitigating the risks were performed.

10. The acceptable risk can be achieved by hazard reduction of disasters, which are only connected with human activities, and above all by reduction of vulnerability of a given subject that is an object of risk assessment. 
To ensure the subject security the subject assets governance has to be established on the safety management that is proactive and it is based on project and process approaches that are concentrated to good handling with risks that are inherent to a given subject. If with risks are not dealt correctly, so it is impossible to reach successfully targets, and therefore, the feasibility of procedures is reviewed in advance [3]. The relevance of risk roles is caused by a fact that the costs of project / process target implementation and the all successfulness depend on a risk distribution. Therefore, it is necessary that each project may hold a special structure, risk distribution and financing that correspond to its character.

The risks have different sources, i.e. they depend on the disasters, local vulnerabilities, methods of defeating and on response management, they originate on side of all participated stakeholders. To reach comprehension and following risk reduction it is necessary to perform its analysis that consists in the following phases: risk identification; risk assessment; risk allocation including the risk and the risk assignation to participated subjects; risk treatment; and continuous monitoring and in a case of need the application of corrective measures.

The risk management model directs the subject to a continuous proactive risk management that leans on the promt identification, analysis, countermeasure planning, monitoring and governance of risks. Each risk passes through these steps at least once, and often several times [3], [7-9]. In the first step there is determined the risk source, the character of possible failure, operational and commercial connections. In the second one there is determined the probability and impact (for calculation and mutual risk comparison). In the third one there are defined countermeasures leading to the risk elimination, risk transfer to somebody else, negotiation with risk or its impact. In the fourth one there is obtained information on changes of individual risk elements in time. In the fifth one there are performed planning actions as reactions to appurtenant changes.

Outputs from risk management process for need of assets governance are the following:

1. Risk assessment document - including the all information on appurtenant risk.

2. Top risks list - including the list of selected risks, the solution of which has the highest demands on sources and time.

3. Retired risk list - serving as historical reference for future decision-making.

The safety management in comparison with the classic risk management uses the set of optimal measures against to all possible disasters respecting the physical nature of disasters possible in a given subject and it includes the precaution principle in concept promoted by the European Union at present [4]. Therefore, on the basis of present knowledge analysis, performed in work [3], [6], there is necessary for ensuring the security and sustainable subject development to change the standard risk management to the risk governance profiting the safety, called safety management. It is necessary to:

- establish synergic relations among the risks, vulnerability and safety,

- model the process of decision-making the public administration with regard to risks and uncertainties (to perform support decision-making systems),

- specify legal conditions and protected measures,

- improve activities of institutions (institutional changes). 
Everyday facts and analyses of behaviour of both followed systems show that risks are going reality and that during the time new risks emerge. Therefore, it is necessary to live according to the concept of live with risks [10].

Reduction of each risk is connected with a cost increase, with a lack of knowledge, technical means etc. Therefore, in practice we search for boundary to which it is reasonable the risk reduction in order that expended costs may be reasonable. This level of risk reduction (certain optimality) is mostly a subject of top management and of political decision-making, at which there are used the present scientific and technical findings and considered the economic, social and other conditions.

The basic turn of a subject management with regard to required targets is not possible to reach by individual partial measures, but only by a complex approach. To ensuring the security and sustainable development of subject there is necessary to use the co-ordinated and intentional approach. It enables step by step and in agreement with their importance and urgency to solve set of tasks in all domains and parts and by this to reach the required subject state [3].

Both followed management systems fulfil demands above put on safety management system - see to [3] and www.epa.gov.ems/, www.inem.org.

\section{Real Preventive and Mitigation Measures and Activities}

As it was above said at the disaster occurrence there are originated chains of undesirable phenomena (impacts, consequences) of external and internal character, primary and secondary, which affect negatively the subject under consideration in different intensities and in different time moments. The substantial role plays the local vulnerability of subject and pertinent faults in a human behaviour or management on all levels.

With regard to the historical development there are a lot of preventive and mitigation measures that are applied into practice by legal rules, technical standards and norms and public instructions. These ensure the protection against to design basis disasters. In the case of beyond design disasters this protection does not exist and severe harms, damages and losses are caused not only by direct impacts on system safety but also through interdependencies arranged by couplings created in system by links and flows of a permanent or random character. These secondary impacts mostly affect the system assets and the system security strongly and lengthy [11].

For both considered management types the land-use planning plays a big role because it ensures a basic prevention against disasters of all kinds; i.e. natural, technological, environmental, social and those caused by interdependencies in the critical infrastructure, including the terrorist attacks. In the frame of safety management there are performed measures in the land-use planning, designing, building and operation of objects and infrastructures. The measures are technical, legal, organisational, economical etc. [11]. For this management type there is necessary:

1. To consider all disasters that can occur in the subject under account (so called "All Hazard Approach" [12]).

2. At possible disasters there is necessary to take into account hazards of the 10th, 100 th and may be more year disasters. 
3. To carry out measures for vulnerability (and risks) reduction against disasters that can have unacceptable impacts on the subject assets.

4. To carry out mitigation measures against unacceptable impacts on the assets, the occurrence of which cannot be prevented.

5. To concentrate to critical assets, critical functions and critical activities which create the base for fulfilment of management aims in the subject.

6. From the economical viewpoint it is necessary to implement only measures suitable for a given subject and effective not only in the limit time interval but in reasonable time period.

For realisation in practice there is necessary:

- formation (generation) of professional background for the decision making by the research and science support,

- application of suitable management structure that will ensure the rational and qualified planning the measures,

- building up and training the executive forces,

- specialist training and systematic population education,

- legal regulations, norms and standards,

- inspections and other check mechanisms including the QA system,

- special management types for emergency and critical cases.

From this it follows that a great role at creation of safe space there is played by level of management. As it was said above the subject management has to be proactive, come out from sophisticated grounds, be tailored to real conditions and understandable to all subjects to which it is addressed. That it is necessary in order that the subject top management might recognise that the safety is not something in advance given, but that it must be created by conscious, directed and linked system measures and interventions, which from the theory viewpoint means to carry out management of safety [3], [13]. If we consider the emergency situation scale with degrees $0-5$ [3], the subject safety management ensures:

- each human is capable to put under control the emergency situations of the $1-2$ categories due to his/her education, training and preparation,

- subject top management has the emergency management system for successful defeating the emergency situations of the 2 - 4 categories,

- subject top management has the crisis management system for successful defeating the emergency situations of the 5 category (i.e. the crisis).

In the frame of mentioned management systems, the public administration and considered subject top managements and their administrative sections:

- build executive forces (fire-fighters, security guards, technical services, cyber safeguard etc.), that are prepared and trained for putting under the control the emergency situations, 
- form financial and material resources in order to they may put under the control all possible emergency situations,

- form the temporary systems which ensure the executive forces support under critical situations.

For ensuring the subject stability and its sustainable development there is necessary to ensure the continuity, i.e. the survival of emergency and critical till crisis situations [14]. To this aim there is necessary to perform minimally the risk management and optimally the safety management. The risk management is a planning, organisation, allocation of work tasks and check-up of resources of organisation so that there might be reduced losses, damages, harms, injuries or deaths caused by various disasters. The safety management consists in a planning, organisation, allocation of work tasks and check-up of sources of organisation with target to reach requested safety level. Its targets are higher than the risk management goals. It includes the principals that are important for sustainable development [3], i.e.:

- adequate expenses principle (i.e. the spent expenses on measures must be optimal it must not happen wasting),

- integration principle (i.e. the activities in domain of one protected interest must also take into account the impacts on other protected interests - it goes on finding the mutual balance),

- preliminary cautions (precaution) principle (i.e. there is necessary to perform the prevention and mitigation measures also then, when there is a very low probability that undesirable severe impact will occur, i.e. it does not rely on size values obtained by common statistical methods, but on the results of methods based on extreme values or marginal estimate),

- prevention principle (i.e. at a decision making there is taking into account the experience that in a time scale comparable to the human life they are generally preventive measures feasible and financially less exigent than corrective measures, and quite it pays when we take into account the needs for the next generation existence),

- synergy principle (i.e. in case that there are possible several variants, so there might be preferred such variant, that is an optimal one from the view of strategy and accessible resources - there is recommended the proactive management application),

- subsidiary (decentralisation) principle (i.e. the problems might be solved on the lowest possible level - there are recommended methodologies for the regional level of public administration),

- public space cultivation principle (i.e. there is assumed the participation of the state authority, public administration, their executive and other forces, research and professional bases, legal and physical persons and citizens),

- partnership principle (the relations among the protected interests are equivalent),

- openness and transparency principle (groundwork, decisions and their justification are accessible for public), 
- exactness principle (i.e. there is came out from scientifically well-founded, measurable and checked up concept tasks and measures, which are short-term, mediumterm or long-term character),

- well-judged receiving the ecological and other liabilities principle (i.e. there is enforced that ecological and other liabilities cannot be accepted without responsible evaluation of their impacts on further protected interests).

Both followed management systems fulfil demands put on safety management system - see to [3] and www.epa.gov.ems/, www.inem.org.

\section{Groundwork for Management}

A clear model of the safety management system (SMS) has been established based on current knowledge [3], [6], [13], Figure 3. It is necessary to note that this SMS model applies to systems with not very complex structure and with clearly defined relationships and flows among the elements of the system. Even here, however, considering the diversity of systems that are object of management, it is necessary to elaborate each particular SMS in accordance with a concept that respects the individual structure and specifics of a system, by which we replace the object that we want to manage. By such concept we also determine risks that we follow and the way of their consideration, i.e., if process of decision making is based on evaluation of results of partial, integrated or integral risks. It has to be emphasized that only the integral ones include the cross sectional risks that are associated with internal dependencies among interconnected assets of system or among interconnected individual systems in a case of system of systems (SoS - System of Systems) [6].

According to a current knowledge, the real systems like the human system, critical infrastructure, environment, human society, human body etc. are complex systems that consist of several systems of different nature and different locations that are interconnected and aimed to ensure certain operations and activities in a specific place and time and in a certain quality. It is necessary to note that there is a fundamental difference between the complex system which we have been monitored and managed for several decades, and the SoS, which we have systematically examined in recent times [6].

A complex system is a set of interconnected systems which have closed architecture. This model nowadays represents foundation for management of power [15], gas, heat, and water, supply systems etc. According to the nomenclature of engineering disciplines focused on safety [4], the aim of such systems is to ensure system security, whereas no attention is paid to the system surroundings or to neighbouring systems. Therefore, e.g. in a case of black-out of electricity supply system, the electricity distribution management system only deals with technical problems associated with the restoration of electricity supply and it does not address to issues of impact of such power failure impacts on lives of people, on running businesses, etc., i.e. on public assets [15]. 


\section{Safety Management System}

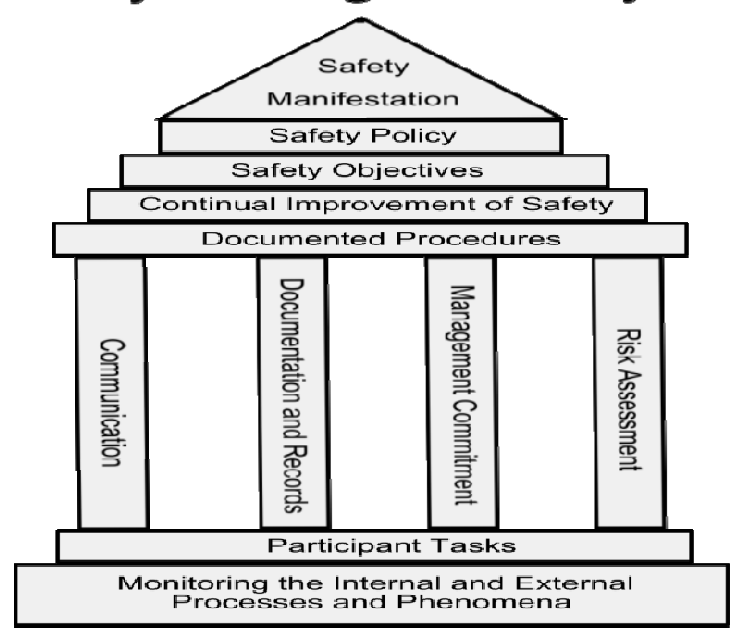

Fig. 3. A general model of the safety management system of real objects

On the other hand, the current SoS concept is understood as a set of interconnected systems which have open architecture, i.e., different elements are connected as long as they fulfil the conditions of interoperability and user requirements [16]. With regard to the above-mentioned public assets, the aim of SoS safety management is to ensure not only the safe SoS as such, but also its safe surroundings, i.e. its goal is not just a system security, but also requirement that the system does not threaten its surroundings, i.e. it goes on the integral safety management [3], [16]. In other words, the SoS safety management system takes into account requirements of surroundings, e.g. such as demands of electricity users etc. From the above it is clear that the concept of SMS for SoS is different from those for complex systems now commonly used in a practice.

Qualified SMS for the SoS safety management are currently being looked for. They have to deal with internal dependencies among systems and appropriately resolve conflicts among systems of different nature. Conflict resolution with aim to ensure the SoS safety in the real environment means finding a consensus among aims of individual systems and among ways of their reach; priority target for SoS safety is coexistence of partial systems [17].

The biggest challenge for SoS safety management systems are the identification, understanding and appropriate management of cross-cutting risks which cause or can cause different cascades of failures of SoS functionality, which deplete the SoS assets. For their discovery and strategic management it is necessary to analyse internal dependencies among SoS individual systems, across entire SoS and between the SoS and its surrounding. Systems of systems have specific properties such as nonlinearity, different steady states (attractors), catastrophic behaviour, chaotic behaviour, etc., which are the cause of cross-cutting risks that disturb both, the followed SoS security and the SoS vicinity security [6]. In order to ensure the safe SoS and safe SoS vicinity, we have to be able to cope with the cross-cutting risks, i.e. to identify and appropriately manage them. 
We have to realize that for SoS risk management it is valid basic knowledge of risk management domain [6], i.e. it is not enough to know the risk size, but it is necessary to know its specific causes, their localisation in a controlled system and the particular vulnerabilities of assets in a given allocation. For identification, analysis and assessment of risks, there are many classical methods, tools and techniques [6]. Unknown there are the tools, methods and techniques for identifying, analysing and managing the cross-cutting risks.

With regard to the Czech national project results [11] there is necessary for needs of safety management of a given subject to ensure qualified replies to the following questions:

1. What disasters can occur in a given subject and what impacts have they?

2. Where disasters can occur and how their impacts are spread in a given subject?

3. Under what conditions can disasters occur in a given subject and what conditions can cause escalation of their impacts?

4. How often can disasters occur in a given subject?

5. From what disaster sizes have disasters in a given subject unacceptable impacts, that caused losses, harm and damages on assets?

6. What maximum sizes could reach disasters in a given subject?

7. What assets damages can be caused by maximum possible disaster on specified credibility level in a given subject and what are its impacts on a given subject?

8. What is possible to do in a given subject against unacceptable disaster impacts on section of land-use planning, design, construction and operation of civil and technological objects and infrastructure, and may be in other domains as are the monitoring, inspection, education etc. with the aim to prevent the occurrence of disasters if possible or at least to prevent or to mitigate unacceptable impacts by preventive measures, preparedness, fit response to a disaster and by renovation, at which there has to be respected the losses prevention and targets of sustainable development?

9. What are necessary measures against real disasters in a given subject in the technical, organisational, financial, social, legal, education and training domains?

10. What unacceptable and residual risks (i.e. undesirable impacts with probability occurrence superior to a limit stipulated) with regard to possible disasters in a given subject will stay, when there are fulfilled rational measures that public administration can ensure in the technical, organisational, financial, social, legal, education and training domains?

11. How does perform the response to disaster with an aim to stabilize the subject state and to start renovation.

12. How does perform the renovation of subject and its assets with an aim rationally to use resources, forces and means for the prohibition of further losses, the upgrade of resistance against possible disasters and for the start of further subject development with all items on which it is dependent?

13. What is suitable the form of management and of a given subject renovation and its assets performance after disaster and how is it possible to realise it?

14. How does create the financial / monetary reserve for a rational renovation of a given subject and of its assets after disaster? 
Then, for the subject safety management there is necessary with regard to hazard size and local vulnerability to divide known disasters into the following groups:

- disasters which cannot have impacts on a given subject,

- disasters which have only acceptable impacts on a given subject, i.e. the relevant disasters,

- disasters which have on a given subject only such impacts that might be put under the control at performance of preventive and mitigation measures, i.e. the specific disasters,

- disasters which have on a given subject inadmissible impacts, and hence there is necessary to carry out the principal preventive measures the technical, organisational, legal and educational domains, i.e. the critical disasters which cause or can cause crisis situations.

The human system safety management of territory is based on these data [3], the environmental management system is so in-depth only in some cases - see www.epa.gov.ems/, www.inem.org (the environment impact assessment and strategic environment assessment are not so detailed).

\section{$5 \quad$ Procedure for Ensuring the Safety, Continuity and Sustainable Development of Subject}

With regard to results in works [3], [5], [7], [10-11], [14] there is necessary for the subject safety ensuring to consider and to evaluate all disasters that have or can have unacceptable impacts on the subject, i.e. above all to determine disasters that have unacceptable risks which are impossible to avert by measures performed in advance and to split up them on:

- specific, which may put under control by qualified and in-depth preparedness of response to these disasters using the standard forces, measures and resources,

- critical, which may put under control by standard and beyond standard forces, measures and resources including the limitation of the rights and freedoms of staff and citizens.

After this sorting there is necessary to specify and to apply measures for averting the disasters or their unacceptable impacts there, where it is possible, and there, where it is impossible to prepare in the frame of preparedness to response the measures for mitigation of unacceptable impacts.

The human system safety management of territory respects these facts [3] and the environmental management system goes on so in-depth only in some cases - see www.epa.gov.ems/, www.inem.org.

\section{$6 \quad$ Planning for Safety Management Needs}

Because there is a reality that it is impossible to avert some of unacceptable disaster impacts on assets being important and mostly requiring the investments, and because 
it is impossible to ward off by preventive measures, because they either do not exist or are not accessible financially, technologically or personally, therefore, there is necessary to perform emergency and crisis planning in a given subject.

The planning is consciously regulation of development. It is conscious activity of a subject management that consists in the selection and presuming the aims, tasks, variants and ways, which condition the achievement of these aims. The most important feature of planning is the selection of aim. The planning is not the make-up of hierarchical commands file, which might be unthinkingly fulfilled, it is a creative activity, which stipulates the real aim and determines the optimal way for its achievement. The planning is a fundamental section of each management. For achievement of the long-term aims there is used the strategic planning and for achievement the short-term aims objectives the operative planning; both have their particularities, which pre-determinate the selection of methods and ways.

The human, however, wants and has to do either preceding the critical situations or put under a control the emergency, critical and crisis situations, and therefore, he / she has to apply a higher attention to the equation "insufficient awareness and insufficient understanding to crisis = insufficient preparedness, which means bad planning". Planning the measures, based on an objective evaluation have to be carried out during the land-use planning, designing, construction and operation, i.e. in the EU it is divided into ex ante, during and ex post.

In the planning domain there is necessary for determination, specification and realisation of preventive and mitigation measures in a case of every relevant disaster to know the impact sizes and their distribution on the area. This groundwork must be prepared by pertinent research and scientific institutions, because they have data and needed knowledge to their interpretation. The role of decision making groundwork lastingly increase with the time, because also during the intervention (response to disaster) there are the disaster characteristics that influence the commander decision making, e.g. the rate of disaster start (sudden or slow beginning), warning, preparation time, size of danger, risks for participants of intervention, casualties, assessment, number of members of executive forces for intervention, stage of disaster development (beginning, period of secondary impacts etc.), main risks, used forces, number of commanders, required decision (routine, known, complex or unknown), sufficiency or insufficiency of material for intervention, knowledge of site, time of intervention, space location (one or more sites).

In the planning domain there is not still uniformity - most often there are used:

- security plan, the aim of which is to arrange the subject needs and development,

- emergency plan, i.e. the set of response plans to emergency situations of the $3-4$ categories for foreseeable emergency situations,

- continuity plan,

- crisis plan, i.e. the set of response plans for putting under control the critical situations,

- contingency plan, i.e. the response plan for unforeseen situation.

The planning in the subject, based on the stipulation of possible impacts and on costs, which a given subject will pay for failure, has to be particularly taken to this assets and property that mostly require investments at renovation [3]. 
The human system safety management of territory respects these facts [3] and the environmental management system respects these facts only in some cases - see www.epa.gov.ems/, www.inem.org (no obligatory realistic response plans to emergency and critical situations).

\section{Comparison of Human System Safety Management and Environmental Management}

From the above given results there is clear that both followed management types, i.e. the human system safety management and the environmental management in the sense of environment safety management are based on advanced risk management and that the human system safety management has more tools supporting the safety (all hazard approach, procedure for disaster assessment, emergency plans, crisis plans). Logic comparison of basic items shows that considered management types differ by:

1. Assets, i.e.:

- environmental management has one asset "environment" and in advanced concept of the EU three pillars (environment, social, economic) [4],

- human system safety management has several public assets and environment is only one of them (Figure 1).

2. Aims, i.e.:

- recent environmental management is aimed to secure environment with sustainable development enabling the human existence; the first is environment needs and the second human needs (www.epa.gov/ems; www.inem.org), which does not enable to solve human needs in the sense of Maslow pyramid [18],

- human system safety management is aimed to secure human system with sustainable development and it also takes care on environment but not as the main priority but as one of basic system assets, i.e. it has a chance to solve human needs in the sense of Maslow pyramid [18].

Regarding these facts we can conclude that for humans the human system safety management is more acceptable because it has a chance to fulfil human needs in the sense of Maslow pyramid [18]. But the present problem is that we have not enough knowledge on interdependences among the human system assets that are sources of cross-section risks, on criteria and limits for negotiation with all types of risks existing in the human system. The aimed research is very necessary.

\section{Conclusion}

The security situation in the world, territory and organisation has been changing with the time, and therefore, there must be systematically built the safety culture, which taking into account actual piece of knowledge and experience. The safety culture 
promotion into practice requires both, the aimed management and the broad participation of all staff of a subject under consideration with emphasising that the top management has the biggest responsibility. It understandably leads to the assignment of higher priority to planning and safety management as well as to higher demands to the understanding level of all participants.

Facts given above show that for effective management of all risks to both subjects considered, the environment and the territory represented by human system, there is necessary to apply in the subject under account the sophisticated safety management. This represents integral, complex and system tool ensuring the subject safety and enabling its development. It acts in dynamically uncertain surroundings and systematically ensures the stability (prevention of crisis) and forms conditions for the next development. It leans on the monitoring, situation diagnostics, sophisticated analyses and processes appreciation, prediction of further process development, preventive and mitigation measures application before activities start and in their course, preparations of measures for correction of undesirable processes development or for putting under a control the undesirable processes development and for ensuring the renovation etc. All partial tools are one another linked and sequenced by a way that leads to a synergic effect [19].

The differences between the followed management types are in the priority aims: for environmental management the aim is to ensure secure environment with sustainable development enabling the human existence; and human system safety management is aimed to humans, however, it also respects the other assets among which is also the environment. If we stipulate that humans build the system for them, so we must agree that human system safety management inherently includes the environmental management by way that is more acceptable for humans. It means that we could not create too many management types in practice but to create only one which will build world for humans on a correct base.

Acknowledgement. The author thanks for support to the Czech Technical University in Prague, the EU - project CITI-SENSE, ENV.2012.6.5-1, grant No308524.

\section{References}

1. UN: Human Development Report. New York (1994), http: / /www . un . org

2. Raven, P.H., Berg, L.R., Johnson, G.B.: Environment. Saunders College Pub. (1998)

3. Procházková, D.: Strategic Management of Safety of Territory and Organisation. ČVUT, Praha (2011)

4. EU: European Commission Adopts Communication on Precautionary Principle. Brussels (2000), http://europa. eu.int/rapid/pressReleasesAction.do? reference $=$ IP $/ 00 / 96 \&$ format $=$ ML\&aged $=0 \&$

language $=E N \& g u i$ Language $=e n$

5. A Guide to the Project Management Body of Knowledge. US Project Management Institute, Washington (2004)

6. Procházková, D.: Risk Analysis and Risk Management. ČVUT, Praha (2011)

7. OECD: Assessing Societal Risks and Vulnerabilities. OECD Studies in Risk Management, Denmark, Paris (2006) 
8. EU: Risk Assessment and Mapping Guidelines for Disaster Management. Working paper SEC(2010) 1626. Brussels (2010).

9. ISO: Draft International Standard ISO/DIS 31000, Risk management - Principles and guidelines on implementation (2008)

10. US ISDR: World Conference on Disaster Reduction Declaration. Kobe (2005), http: / / www. un.org

11. Procházková, D.: Methodology for Estimation of Costs for Renovation of Property in Territories Affected by Natural or Other Disaster. SPBI SPEKTRUM XI Ostrava (2007)

12. FEMA: Guide for All-Hazard Emergency Operations Planning. State and Local Guide (SLG) 101. FEMA, Washinton (1996)

13. OECD: Guidance on Safety Performance Indicators. Guidance for Industry, Public Authorities and Communities for developing SPI Programmes related to Chemical Accident Prevention, Preparedness and Response. OECD, Paris (2002)

14. Disaster Advisors Inc.: Bussiness Continuity Planning (2003), http: / / www. disasteradvisors.com/disasterplanning.htm

15. Procházková, D.: Real Problems of Critical Infrastructure Threatening the Region safety. In: Ale, Papazoglou, Zio (eds.) Reliability, Risk and Safety, pp. 2387-2394. Taylor \& Francis Group, London (2010)

16. Procházková, D.: Critical Infrastructure Safety. ČVUT, Praha (2012)

17. Bossel, H.: Systeme, Dynamik, Simulation - Modellbildung, Analyse und Simulation komplexer Systeme. Books on Demand, Norderstedt/Germany (2004), http: / / www. libri.de

18. Maslow, A.H.: Motivation and Personality. Haper, New York (1954)

19. EU: FOCUS, http: //www. focusproject. eu 